\title{
Interoperability between central counterparties
}

\author{
Jürg Mägerle and Thomas Nellen
}

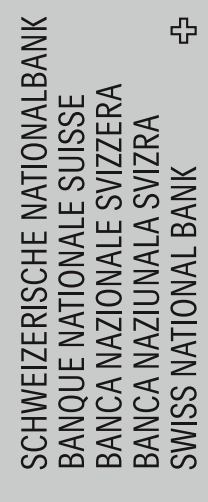

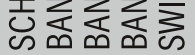

a 
The views expressed in this paper are those of the author(s) and do not necessarily represent those of the Swiss National Bank. Working Papers describe research in progress. Their aim is to elicit comments and to further debate.

\section{Copyright $\odot$}

The Swiss National Bank (SNB) respects all third-party rights, in particular rights relating to works protected by copyright (information or data, wordings and depictions, to the extent that these are of an individual character). SNB publications containing a reference to a copyright ( $\odot$ Swiss National Bank/SNB, Zurich/year, or similar) may, under copyright law, only be used (reproduced, used via the internet, etc.) for non-commercial purposes and provided that the source is mentioned. Their use for commercial purposes is only permitted with the prior express consent of the SNB.

General information and data published without reference to a copyright may be used without mentioning the source.

To the extent that the information and data clearly derive from outside sources, the users of such information and data are obliged to respect any existing copyrights and to obtain the right of use from the relevant outside source themselves.

\section{Limitation of liability}

The SNB accepts no responsibility for any information it provides. Under no circumstances will it accept any liability for losses or damage which may result from the use of such information. This limitation of liability applies, in particular, to the topicality, accuracy, validity and availability of the information.

ISSN 1660-7716 (printed version)

ISSN 1660-7724 (online version)

๑ 2011 by Swiss National Bank, Börsenstrasse 15, P.0. Box, CH-8022 Zurich 


\title{
Interoperability between central counterparties
}

\author{
Jürg Mägerle, Thomas Nellen* \\ Swiss National Bank ${ }^{\dagger}$ \\ Bundesplatz 1, P.O. Box, CH-3003 Bern \\ E-mail: juerg.maegerle@snb.ch, thomas.nellen@snb.ch
}

August 10, 2011

\begin{abstract}
In reaction to recent requests for interoperability between central counterparties of European stock markets, regulators have issued new guidelines to contain systemic risk. Our analysis confirms that the currently applied cross-CCP risk management model can be a source of contagion, particularly if applied in multilateral frameworks. While regulators' new guidelines eliminate systemic risk, this comes at the cost of an inefficiently overcollateralised clearing system. We discuss further approaches that contain systemic risk while reducing or eliminating overcollateralisation. Interoperability is of economic importance as it may contribute to the efficiency and safety of a worldwide fragmented clearing infrastructure.

JEL classification: E42, E58, G01, G28

Key words: interoperability betwenn central counterparties, financial network, systemic risk, netting efficiency
\end{abstract}

\section{Introduction}

This paper investigates the risk management of financial exposures resulting from links between central counterparties (CCPs). Such links are referred to as interoperability. On the one hand, interoperability enables multilateral netting of trading positions among all participants of interoperating CCPs, thereby reducing the overall financial exposure within the clearing system. Furthermore, it allows securities traders to access multiple markets via a single CCP. Consequently, interoperability facilitates direct competition between CCPs, an objective pursued by the European Union to encourage consolidation of the fragmented European clearing industry. Fragmentation is not only an issue in

${ }^{*}$ We are indebted to Ernst Baltensperger, Marco Cecchini, Darrell Duffie, Philipp Haene, Béatrice Kraus, Antoine Martin, Klaus Neusser, Robert Oleschak, Andy Sturm, participants of the Brownbag Seminar at the University of Berne 7 September 2010, of the GFRI/FINRISK/SFI Conference on Financial Networks 10 June 2011, of the BIS Research Seminar 14 June 2011, of the Economics of Payments V Conference hosted by the Federal Reserve Board and the Bank of Canada 23/24 June 2011, of the Research Seminar at the Bank of Canada 8 July 2011 and an anonymous referee for helpful comments.

$\dagger$ The views expressed in this paper are those of the authors and do not necessarily represent those of the Swiss National Bank. 
European cash equity clearing, but is also globally present in many other areas, such as the emerging clearing of over-the-counter (OTC) derivatives. On the other hand, interoperability creates financial exposures between CCPs and can give rise to systemic risk. As a reaction to the financial crisis, central counterparty clearing has gained momentum, both driven by market demand as well as regulatory reforms such as the G-20 proposal for mandatory clearing of OTC derivatives. Linking central counterparties through interoperability is of economic importance as it may help to overcome inefficiencies related to a worldwide fragmented clearing infrastructure.

The currently applied cross-CCP risk management model of European cash equity CCPs has raised systemic risk concerns among some European financial regulators. ${ }^{1}$ In response, regulators have issued new guidelines on how to structure cross-CCP risk management models. Analysing the currently applied cross-CCP risk management model, we find regulators' systemic risk concerns to be justified. However, while the new guidelines effectively contain systemic risk, they leave the clearing system inefficiently overcollateralised. Therefore, we introduce alternative cross-CCP risk management models that address systemic risk concerns while reducing or eliminating overcollateralisation.

Interoperating European cash equity CCPs currently cover cross-CCP exposures via the rehypothecation of collateral collected from their participants. ${ }^{2}$ Regulators claim that margins collected from CCPs' members may be insufficient to cover these exposures. Since cross-CCP exposures may easily exceed a CCP's own capital, regulators suspect that undercollateralisation may become a source of systemic risk. Due to interoperability arrangements, the default of a CCP may easily spread across the linked clearing system. Therefore, the authorities regulating those CCPs that are most actively pursuing interoperability initiatives have issued new guidelines on how to structure cross-CCP risk management models. ${ }^{3}$ These guidelines require cross-CCP exposures to be fully collateralised and to be covered by extra collateral that is funded via financial resources other than the members' ordinary margin contributions to collateralise exposures vis-à-vis the CCPs.

We analyse the currently applied cross-CCP risk management model by deriving conditions for sufficient collateralisation of cross-CCP exposures. Indeed, undercollateralisation emerges as a valid concern. This already applies for bilateral interoperability frameworks if CCPs apply margin models that are too distinct. Worse, multilateral interoperability arrangements - involving three or more CCPs - are generally prone to undercollateralisation, even if the involved CCPs apply identical margin models. Thus, a default by a CCP could have a domino effect among CCPs. According to our analysis, regulators' new guidelines eliminate the risk of undercollateralisation. However, the funding of cross-CCP exposures by means of additional collateral on top of existing financial resources results in an overcollateralised clearing system. That is to say,

\footnotetext{
${ }^{1}$ See "LCH.Clearnet in last-minute hitch", Financial Times, Friday 30 October 2009, and "Clearers' linkages may introduce new risks", Financial Times, Saturday 15 February 2010. The appendix provides a more detailed discussion.

${ }^{2}$ For a definition of rehypothecation, see Committee on Payment and Settlement Systems (CPSS) (2003).

${ }^{3}$ For a discussion of guidelines, see European Commission (2009). These guidelines go beyond international minimum requirements issued by the CPSS and the Technical Committee of the International Organization of Securities Commissions (IOSCO). See recommendation 11 in CPSS/IOSCO (2004) and the discussion in the appendix.
} 
the collateral requirements of interoperability arrangements would substantially exceed those of a single CCP, if regular margins provided by members cannot be used to cover cross-CCP exposures.

Margins are generally characterised as a defaulter-pays instrument. However, if a CCP rehypothecates its members' margins to another CCP, margins change into a survivors-pay instrument. This transformation of margins' creates additional collateral. ${ }^{4}$ Based on this observation, we investigate two alternative cross-CCP risk management approaches that reduce or avoid excessive collateralisation without rendering CCPs prone to undercollateralisation. In particular, the establishment of a meta-CCP - i.e. a CCP for CCPs - eliminates undercollateralisation without requiring any additional financial resources. From this perspective, regulators' new guidelines increase the cost of collateralisation without necessarily increasing the safety of the clearing system.

This paper is related to Duffie and Zhu (2011). Our stylised model illustrates the efficiency gains of central clearing with a single CCP compared to a fragmented clearing structure with multiple but isolated CCPs. The results are in line with Duffie and Zhu (2011), who demonstrate that netting efficiency might be reduced and counterparty risk might even be exacerbated if more than one CCP is present. We go beyond Duffie and Zhu (2011) by illustrating that interoperability may resolve the issues of a fragmented clearing system. In particular, we show that a clearing system with multiple interoperating CCPs can achieve the same netting efficiency as a clearing system with a single CCP. This result is relevant with respect to the clearing system more generally. For instance, Duffie, Li and Lubke (2010) emphasise that the market structure which is emerging for the clearing of OTC derivatives is likely going to be fragmented.

The paper is structured as follows: Section 2 reviews the existing literature on CCPs. The stylised model is presented in section 3. Section 4 analyses a bilateral interoperability framework that covers cross-CCP exposures by means of rehypothecated members' margins. Multilateral interoperability is investigated in section 5, and section 6 evaluates alternative risk management models. The final section summarises the paper. The appendix offers a brief discussion of the risk management and regulation of a single CCP and of interoperability. Furthermore, it briefly examines the new guidelines.

\section{Literature}

While our paper is the first to analyse risk management models for interoperability, many others have analysed aspects of risk management techniques of an isolated CCP. Various studies investigate the optimal size and calculation method for margin requirements. Kupiec (1994) and Kupiec and White (1996) evaluate the degree of risk protection from margin requirements. Others, such as Gemmil (1994), Bates and Craine (1999) and Shanker and Balakrishnan (2005), analyse whether margins in combination with other financial resources sufficiently protect CCPs. Knott and Mills (2002) provide an overview of these and similar studies.

Other papers investigate incentive effects of different risk management frameworks. The effects of limited collateral availability are discussed in Hartzmark (1986), Hardouvelis and Kim (1995) and Gibson and Murawski (2008). The

\footnotetext{
${ }^{4}$ For a more detailled discussion, see the last subsection of the appendix.
} 
moral hazard problem engendered by establishing a collective default fund is analysed in the context of payment systems in Kahn and Roberds (1998). Koeppl and Monnet (2009) discuss an economy with time-critical trades, scarce liquidity and limited enforcement of trades. They illustrate that efficient trading behaviour is achieved if a CCP allows for default losses to occur. To cover such losses, a CCP optimally uses margins and, if the default problem becomes more severe, should first impose a loss sharing agreement and then position limits. Haene and Sturm (2009) investigate the optimal allocation of financial resources between a defaulter-pays and a survivors-pay instrument.

During the recent financial turmoil, CCPs demonstrated their robustness. However, the CCPs' scope is currently challenged by proposals to clear more complex financial products such as OTC derivatives. The fundamental welfare effects resulting from the sharing of default risks are analysed in Pirrong (2009); the benefits of a CCP are investigated under the assumption of asymmetric information. Koeppl, Monnet and Temzelides (2009) analyse optimal clearing arrangements for various financial products. In a framework with central clearing of regular exchange-traded products and bilateral clearing of OTC products, the combination of both being cleared through a single CCP turns out to be efficient if the clearing of OTC products can be cross-subsidised via the fees for ordinary exchange-traded products. This particularly applies when clearing is costly in terms of credit and liquidity needs. Koeppl and Monnet (2010) analyse the welfare effects of mutualisation in the presence of default risk. They investigate the effect of mandatory CCP services when there is a choice between exchange trading with central clearing and OTC trading with bilateral clearing. They conclude that OTC trading can limit the scope of central clearing, but emphasise that a CCP can go a long way to insure the risk contained in OTC trading.

Closest to our paper is the one by Duffie and Zhu (2011). Provided that central clearing of OTC products is reasonable to a certain extent, the organisation of the clearing system should be considered carefully. Duffie and Zhu (2011) show that if a CCP - dedicated to a particular class of OTC derivatives only - is added to the clearing system, netting efficiency is reduced and the clearing system's counterparty exposures increase. They further illustrate that the counterparty risk and netting inefficiency in the clearing system of OTC derivatives is generally exacerbated if more than one CCP is involved. This is in line with our findings for cash equity clearing. We go beyond Duffie and Zhu (2011) insofar as we discuss interoperability arrangements. We demonstrate that interoperability achieves optimal netting efficiency similar to the reference case of a single CCP by enabling multilateral netting across all participants of linked CCPs.

\section{Three Clearing Models}

We consider a market for one security that is traded among an arbitrary number of traders, $i=1, \ldots, k$. Let us denote $t_{i, j}$ as a sale by trader $i$ to trader $j$, i.e. $t_{i, j}$ denotes the short position of trader $i .{ }^{5}$ Consequently, trader $i$ 's long position

\footnotetext{
${ }^{5}$ Because of linearity, the model can easily be extended to any arbitrary number of securities. Also, a trade, $t$, could be further detailed. It consists of the volume of securities, $x$, traded at a certain price, $p$. These variables could be considered as vectors that describe
} 
towards trader $j$ is mirrored by trader $j$ 's short position towards trader $i$. We further assume that $t_{i, i} \equiv 0$, saying that traders do not trade with themselves. Trader $i$ 's gross short position towards all other traders is defined as the sum of his short positions towards individual traders: $\sum_{j=1}^{k} t_{i, j}$. The clearing system's total gross position is $\sum_{i=1}^{k} \sum_{j=1}^{k} t_{i, j}$.

Let the net position of trader $i$ towards trader $j$ be $t_{i, j}-t_{j, i}=x_{i, j}$. This denotes trader $i$ 's short minus long positions. The net position of trader $j$ towards trader $i$ is $t_{j, i}-t_{i, j}=x_{j, i}$. Net positions of a pair of traders always offset each other as $x_{i, j}+x_{j, i}=0$. This also holds true for the entire clearing system's net position:

$$
\sum_{i=1}^{k} \sum_{j=1}^{k}\left(t_{i, j}-t_{j, i}\right)=\sum_{i=1}^{k} \sum_{j=1}^{k} x_{i, j}=0
$$

Because all short positions correspond with a long position - together they constitute a trade - the clearing system's net position is flat. Therefore, bilateral or multilateral net positions are inappropriate indicators of exposures.

We denote the net open position of trader $i$ towards trader $j$ to be the absolute value of the net position, i.e. $\left|t_{i, j}-t_{j, i}\right|=\left|x_{i, j}\right| . \quad\left|x_{j, i}\right|$ depicts the complementary net open position of trader $j$ towards trader $i$. The net open positions of a pair of traders are identical, i.e. both traders have the same exposure towards each other: $\left|x_{i, j}\right|=\left|x_{j, i}\right|$. The aggregate net open position of trader $i$ towards all other traders is the sum of all its net open positions:

$$
\sum_{j=1}^{k}\left|x_{i, j}\right| \geq 0
$$

We determine the clearing system's net open position to be the sum of all traders' net open positions:

$$
\sum_{i=1}^{k} \sum_{j=1}^{k}\left|x_{i, j}\right| \geq 0
$$

In contrast to the clearing system's net position, the clearing system's net open position do not offset each other. Therefore, net open positions proof as valid indicators of the exposures in the clearing system. ${ }^{6}$

\subsection{Bilateral clearing}

Let us assume that - in a bilaterally cleared market - a regulator requires traders to back net open positions with own capital. For that purpose, the regulatory authority defines a capital coefficient of $0<\kappa<1$. The capital coefficient multiplied by a trader's aggregate net open position determines the regulatory

several trades with differing numbers and prices.

${ }^{6}$ Risk management models for cash equity CCPs are usually based on the assumption that the replacement cost risk of short and long positions are identical. The assumption that short and long positions offset each other justifies the linearity of the model. If we consider other than cash equity products, the existence of a counter product (a hedge instrument) is necessary to justify linearity. 
capital charge. $^{7}$ The clearing system's own capital requirement is then defined by the clearing system's net open position multiplied by the capital charge $\kappa$ :

$$
\kappa \sum_{i=1}^{k} \sum_{j=1}^{k}\left|x_{i, j}\right| \geq 0
$$

Figure 1 shows a stylised example of a bilateral clearing system. We will use this example's basic setup throughout the paper. A trade is indicated by a red arrow. Let us assume that each trade involves 100 securities at a price of $\$ 1$ and the capital coefficient $\kappa$ is equal to $1 \%$. Rectangles depict traders and contain the sum of own capital charges, defined as the aggregated net open position of each trader times the capital coefficient. The rectangle from which an arrow originates denotes the trader that encounters a short position, whereas the rectangle the arrow points to denotes the trader with the corresponding long position. Without a central clearing facility, netting only occurs bilaterally. The red numbers in the rectangles denote the traders' capital requirement. A trader's net open position is calculated as the sum of absolute values of short positions minus long positions between each pair of traders. According to expression 4, we sum the red numbers to obtain the clearing system's total capital charge, which equals $\$ 12$.

Figure 1: Example of a clearing system with bilateral clearing

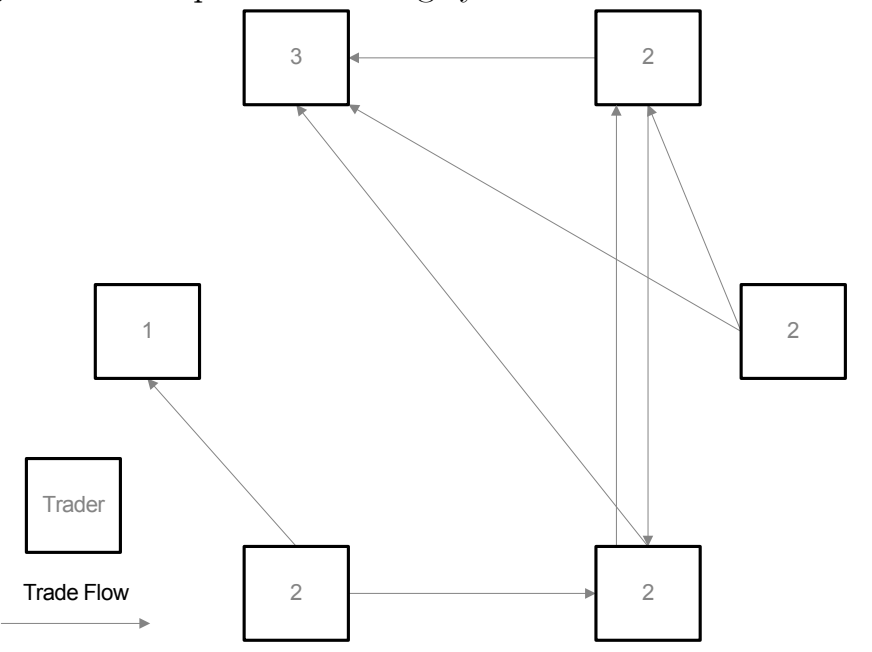

\subsection{Single CCP}

Let us analyse a market that is cleared by a single CCP. The CCP requires traders to provide margins on their net open positions. We define the margin

\footnotetext{
${ }^{7}$ The aim of the latest proposal by the Basel Committee on Banking Supervision (BCBS) is to apply higher capital charges for interbank exposures from trading if these are not secured by a CCP. See Basel Committee on Banking Supervision (2009).
} 
requirement coefficient to be $0<\mu<1 .^{8}$ Because the CCP concentrates counterparty risk, it can apply multilateral netting. This may result in a significant reduction of traders' exposures. Consequently, with a single CCP the cost of collateralisation may be lower than under bilateral clearing.

We denote trader $i$ 's multilateral net open position towards the CCP as follows:

$$
\left|\sum_{j=1}^{k} x_{i, j}\right|
$$

The margin requirement of a CCP is defined as the multilateral net open position multiplied by the margin requirement coefficient. Thus, aggregated margins collected by the CCP are equal to:

$$
\mu \sum_{i=1}^{k}\left|\sum_{j=1}^{k} x_{i, j}\right|
$$

By applying the triangle inequality, ${ }^{9}$ it is easy to see that the clearing system's net open position can be reduced through multilateral netting:

$$
\sum_{i=1}^{k} \sum_{j=1}^{k}\left|x_{i, j}\right| \geq \sum_{i=1}^{k}\left|\sum_{j=1}^{k} x_{i, j}\right|
$$

Inequality 7 states that the clearing system's net open position under bilateral clearing is greater than or equal to the multilateral net open position of a centrally cleared system. Thus if $\kappa \geq \mu$, margin requirements of a CCP are smaller than or equal to the capital charges which the regulator imposes on traders that clear bilaterally. Depending on the reduction of exposures due to multilateral clearing, margin requirements by a CCP might even be lower if $\kappa<\mu$.

Equality in expression 7 is achieved if either no trading takes place - i.e. $t_{i, j}=0 \forall i, j=1, \ldots, k$ - or if traders are exclusively on 'one side of the market' - i.e. each trader exclusively either buys or sells securities. ${ }^{10}$ Thus, in a onesided market, some traders always exhibit short positions of $t_{i, j}>0$, while their counterparts always exhibit short positions of $t_{j, i}=0$. Exactly the reverse holds true for long positions. Thus, a trader's multilateral net open position equals the sum of its net open position:

$$
\left|\sum_{j=1}^{k} x_{i, j}\right|=\sum_{j=1}^{k}\left|x_{i, j}\right|
$$

As a result, inequality 7 collapses to an equality. ${ }^{11}$

\footnotetext{
${ }^{8}$ Standard models applied by CCPs - such as a historical Value-at-Risk (VaR) model essentially result in a margin requirement of a certain percentage of the aggregate net open position of a trader. The linearity of the model is also based on this assumption.

${ }^{9}$ The triangular inequality is defined as $|A|+|B| \geq|A+B|$.

${ }^{10} \mathrm{We}$ do not make any assumptions on the realisation of trade flow patterns. Considering all possible realisations allows us to draw conclusions that are generally valid, irrespective of any market structure. Furthermore, regulators do not take a probabilistic view but require CCPs to be sufficiently collateralised for any arbitrary trade flow pattern.

${ }^{11}$ This is a typical characteristic of money markets. Apart from market-makers, participants are usually on one side of the market, i.e. they are either cash takers or cash lenders. This sharply reduces the effects of multilateral netting. See e.g. Kraenzlin and Scarpatetti (2010).
} 
To summarise, if at least one participant has gross short and long positions towards its counterparties, the implementation of a CCP - i.e. the adoption of multilateral netting - may significantly reduce both the participants' and the clearing system's exposures. Therefore, given similar capital and margin requirement coefficients, the opportunity cost of collateralisation might be smaller if securities are cleared centrally instead of bilaterally.

Figure 2 illustrates the effect of a CCP for the same clearing system as represented in figure 1. Instead of calculating capital requirements on the basis of bilateral netting, a CCP calculates margin requirements on the basis of multilateral netting. The multilateral net open position is easily calculated according to expression 5 , i.e. as the absolute value of the sum of all arrows pointing to a trader's rectangle minus the sum of all arrows pointing away. The red number in a trader's rectangle now indicates the margins charged by the CCP. In our example, the clearing system switches from a capital charge of $\$ 12$ to a margin contribution of $\$ 8$ (given $\kappa=\mu=1 \%$ ).

Figure 2: Example of a clearing system with a single CCP

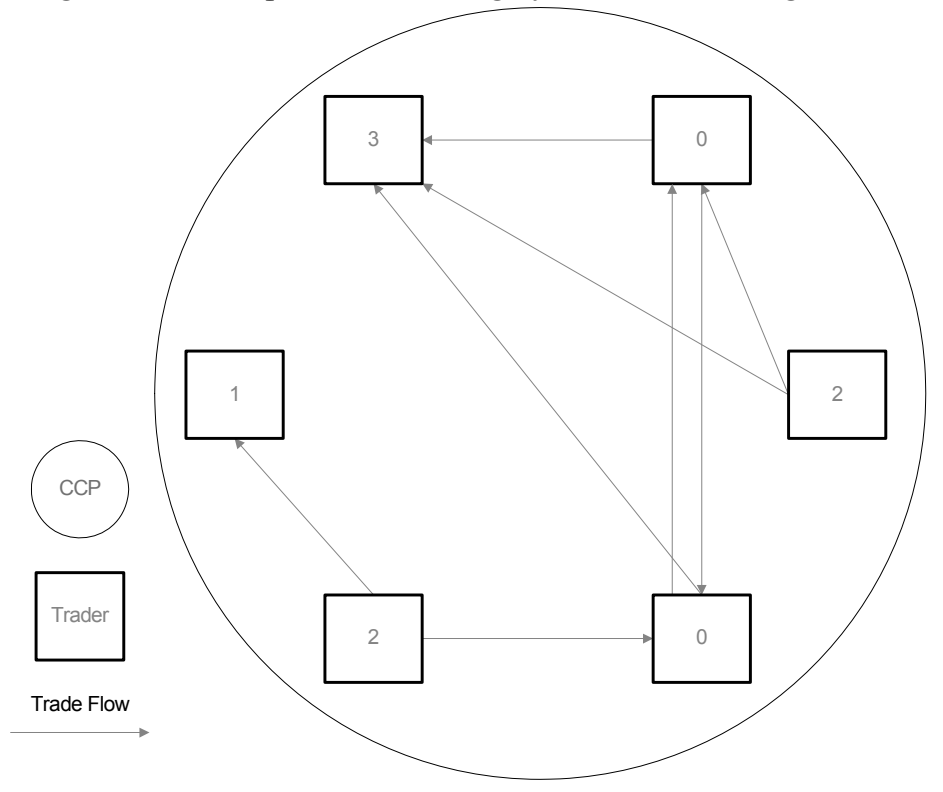

\subsection{Interoperability}

Interoperability enables traders to consolidate their participation in a single CCP. The consolidation of a trader's overall trading activity is beneficial because multilateral netting can be applied to a larger set of trades and between a larger set of traders. ${ }^{12}$

To illustrate this, let us assume that the clearing system consists of two CCPs clearing two different securities, $t^{1}$ and $t^{2}$. CCP1 clears $t^{1}$ and CCP2

\footnotetext{
${ }^{12}$ Traders may also reduce their default fund contributions by consolidating their CCP memberships. In addition traders also safe membership fees, operating costs, etc.
} 
clears $t^{2}$. There is a set of traders $i=1, \ldots k$. All of them participate in both CCPs, which apply the same margin requirement coefficient $0<\mu<1$.

Let us first investigate a situation without interoperability. Each trader delivers separate margins to both CCPs. Total margins collected sum to:

$$
\mu \sum_{i=1}^{k}\left|\sum_{j=1}^{k} x_{i, j}^{1}\right|+\mu \sum_{i=1}^{k}\left|\sum_{j=1}^{k} x_{i, j}^{2}\right|
$$

If traders can net their open positions multilaterally through a single CCP, the following overall margin requirement results:

$$
\mu \sum_{i=1}^{k}\left|\sum_{j=1}^{k}\left(x_{i, j}^{1}+x_{i, j}^{2}\right)\right|
$$

By applying the triangle inequality, it is easy to see that expression 9 is greater than or equal to expression 10. In other words, the margin requirements of two distinct CCPs are greater than or equal to the margin requirement of a single CCP. We assume complete netting between the two securities. Even if a lower level of netting is applied, the linearity of the model ensures that multilateral netting through a single CCP increases netting efficiency. Only if netting between different securities is excluded does a merger not increase netting efficiency. Linearity also ensures that the results apply for any arbitrary number of markets and CCPs. Similar to Duffie and Zhou (2010), we find a single CCP to be optimal as it reduces margin requirements and counterparty risk to the lowest possible extent.

Interoperability enables multilateral netting across all traders of multiple CCPs. We let traders $1, \ldots, l$ be members of CCP1 and $l+1, \ldots, k$ traders are members of CCP2, where $k=l+m$. Then, CCP1 collects margins equal to:

$$
\mu \sum_{i=1}^{l}\left|\sum_{j=1}^{k}\left(x_{i, j}^{1}+x_{i, j}^{2}\right)\right|
$$

while CCP2 collects margins equal to:

$$
\mu \sum_{i=l+1}^{k}\left|\sum_{j=1}^{k}\left(x_{i, j}^{1}+x_{i, j}^{2}\right)\right|
$$

It is easy to see that the sum of margins collected by the two interoperating CCPs equals exactly the margins collected by a single CCP (see expression 10). Thus, in terms of margin efficiency and counterparty risk reduction, interoperability is as efficient as a single CCP.

\section{Bilateral interoperability}

In this section, we analyse interoperability between two CCPs. We investigate whether the collateral collected and rehypothecated by a CCP suffices to cover resulting exposures across the two CCPs. We analyse two cases. First, both 
CCPs apply the same margin model and, second, CCPs apply different margin models. ${ }^{13}$

\subsection{Identical margin models}

We consider a clearing system consisting of one security and two CCPs with $k=l+m$ traders. We let traders $1, \ldots, l$ be members of CCP1 and traders $l+1, \ldots, k$ be participants of CCP2. The margin requirement coefficient for CCP1 is defined as $0<\mu<1$ (and identical for CCP2: $0<\nu<1$ ). For the time being, we assume margin requirement coefficients to be equal, $\mu=\nu$.

Interoperating CCPs enable participants to multilaterally net their trades across all counterparties in the framework. Thus, CCP1 requires margins from its traders equal to:

$$
\mu \sum_{i=1}^{l}\left|\sum_{j=1}^{k} x_{i, j}\right|
$$

while CCP2 collects margins equal to:

$$
\nu \sum_{i=l+1}^{k}\left|\sum_{j=1}^{k} x_{i, j}\right|
$$

Summing the two margin requirements, we find that a single CCP would collect the same margin requirement.

If margins collected by either CCP are greater than or equal to the margins that interoperating CCPs require from each other, we say that CCPs are sufficiently collateralised. If this condition is fulfilled, systemic risk is contained as adequate collateralisation is ensured. By contrast, we say that a CCP is undercollateralised if at least one of the CCPs collects less margin than required by interoperating CCPs. In this case, contagion can occur if a CCP's cross-CCP collateral and its own funds are not large enough to absorb losses caused by the defaulting CCP.

The cross-CCP net position between CCPs is determined similarly, as the net position of a CCP's member towards its CCP. For instance, the cross-CCP net position of CCP1 towards CCP2 is simply the sum of net positions, $x_{i, j}$, between traders of CCP1, $i=1, \ldots, l$, and traders of CCP2, $j=l+1, \ldots, k$. Thus, the cross-CCP net position of CCP1 is determined by:

$$
\sum_{i=1}^{l} \sum_{j=l+1}^{k} x_{i, j}
$$

Cross-CCP margin requirements are calculated as margin requirements for traders, i.e. the cross-CCP net open position is multiplied by the margin coefficient. The cross-CCP net open position is defined as the absolute value of the cross-CCP

\footnotetext{
${ }^{13}$ As margins are only one element of a CCP's risk management model, distinct margin requirements do not necessarily imply that a $\mathrm{CCP}$ with a lower margin requirement is less secure than a CCP with a higher requirement. We do not analyse the allocation strategy of a CCPs' various defence lines as Haene and Sturm (2009) do.
} 
net position denoted in expression 15. Because the short and long positions have the same weight, cross-CCP net open positions are the same for both CCPs: ${ }^{14}$

$$
\left|\sum_{i=1}^{l} \sum_{j=l+1}^{k} x_{i, j}\right|=\left|\sum_{i=l+1}^{k} \sum_{j=1}^{l} x_{i, j}\right|
$$

Therefore, $\mathrm{CCP} 1$ is exposed to a cross-CCP margin requirement by CCP2 equal to:

$$
\nu\left|\sum_{i=1}^{l} \sum_{j=l+1}^{k} x_{i, j}\right|
$$

The necessary and sufficient condition to avoid undercollateralisation of CCP1 is that the margins collected by CCP1 - as denoted in expression 13 - are greater than or equal to the cross-CCP margins that CCP2 requires from CCP1 - as denoted in expression 17 . Thus, CCP1 is sufficiently collateralised if the following condition applies:

$$
\mu \sum_{i=1}^{l}\left|\sum_{j=1}^{k} x_{i, j}\right| \stackrel{?}{\geq} \nu\left|\sum_{i=1}^{l} \sum_{j=l+1}^{k} x_{i, j}\right|
$$

According to equation 1, the right-hand side of condition 18 can be expanded as follows:

$$
\left|\sum_{i=1}^{l} \sum_{j=l+1}^{k} x_{i, j}\right|=\left|\sum_{i=1}^{l} \sum_{j=1}^{k} x_{i, j}\right|
$$

Equation 19 enables us to apply the triangle inequality to condition 18 to verify that sufficient collateralisation of cross-CCP exposures is ensured:

$$
\sum_{i=1}^{l}\left|\sum_{j=1}^{k} x_{i, j}\right| \geq\left|\sum_{i=1}^{l} \sum_{j=1}^{k} x_{i, j}\right|=\left|\sum_{i=1}^{l} \sum_{j=l+1}^{k} x_{i, j}\right|
$$

The same can be derived for CCP 2 as depicted in expression 21:

$$
\sum_{i=l+1}^{k}\left|\sum_{j=1}^{k} x_{i, j}\right| \geq\left|\sum_{i=1}^{k} \sum_{j=1}^{l} x_{i, j}\right|=\left|\sum_{i=1+1}^{k} \sum_{j=1}^{l} x_{i, j}\right|
$$

This essentially says that in a bilateral framework traders cannot increase exposures across CCPs without an equivalent and simultaneous expansion of exposures towards their CCP. This ensures that the margin requirements of a CCP towards its traders is always equal to or greater than the margin requirement of the interoperating CCP.

In summary, provided that both CCPs apply identical margin requirement coefficients, $\mu=\nu$, the currently applied risk management model is not prone to systemic risk.

\footnotetext{
${ }^{14}$ As we assume that a short position has the same exposure as a long position, we allow for complete netting. Consequently, exposures between a pair of CCPs are identical. This does not hold if either short or long positions' exposures a weighted differently.
} 
As illustrated in figure 3 , the cross-CCP margin requirements - as a result of bilateral netting between the two CCPs - are equal to $\$ 2$ (denoted by green numbers). Rectangles within an ellipse - which denotes a CCP - are the traders that clear through this CCP. Traders from the right-hand CCP sell 300 securities to traders of the left-hand $\mathrm{CCP}$ and traders from the left-hand CCP sell 100 securities towards members from the right-hand CCP. Both CCPs are sufficiently collateralised since for each CCP the sum of margins collected (numbers in red) is greater than or equal to the cross-CCP margin requirement (numbers in green). The overall margin requirement of $\$ 8$ is identical to that of a single CCP. As predicted by the model, cross-margin requirements of both CCPs are identical for $\mu=\nu$.

Figure 3: Example of a bilateral interoperability framework

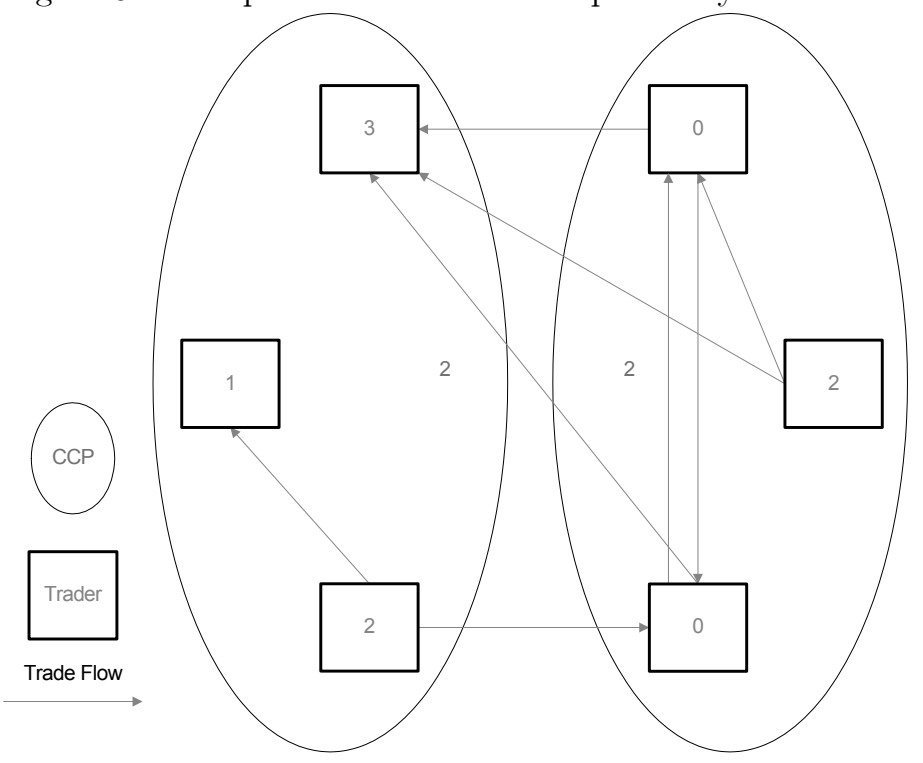

\subsection{Different margin models}

Relevant international standards require that a CCP should be able to withstand the default of its largest participant. In order to meet this requirement, CCPs can implement different risk management models. One CCP may emphasise the defaulter-pays principle (and, thus, high margin requirements), whereas another CCP may give more weight to the survivors-pay principle (and, thus, a high default fund). As a result, margin requirements of any two CCPs typically differ, i.e. $\mu \neq \nu$. Therefore, the question arises whether the above result changes if we relax the condition of equal margin requirement coefficients.

Without loss of generality, we assume that $0<\mu<\nu$. This implies that $\mathrm{CCP} 2$ requires higher margins from $\mathrm{CCP} 1$ than vice versa. Consequently, CCP1 bears a higher risk of being undercollateralised. In order to avoid a degenerate problem, we assume that traders of CCP1 accumulate positive multilateral net 
open positions:

$$
\sum_{i=1}^{l}\left|\sum_{j=1}^{k} x_{i, j}\right|>0
$$

This allows us to rearrange condition 18 for sufficient collateralisation as follows:

$$
1 \geq \frac{\mu}{\nu} \geq \frac{\left|\sum_{i=1}^{l} \sum_{j=l+1}^{k} x_{i, j}\right|}{\sum_{i=1}^{l}\left|\sum_{j=1}^{k} x_{i, j}\right|} \geq 0
$$

The numerator of expression 23 reflects the cross-CCP net open position resulting from trades across CCPs. The denominator depicts the sum of all traders' multilateral net open positions on which the total margin collection of CCP1 is based. From expression 20, we know that the numerator of expression 23 is less than or equal to the denominator, which results in a ratio less than or equal to 1. The ratio of margin requirement coefficients is also less than or equal to 1. However, the ratio of coefficients is not necessarily greater than or equal to the ratio of margins.

The equality of the margin requirement coefficients is a sufficient but not a necessary condition for avoiding undercollateralisation. Whether or not condition 23 holds crucially depends on the difference between margin coefficients chosen by CCPs and the trade flows which CCPs face. The larger the difference of coefficients, the smaller the cross-CCP exposure has to be in relation to the margins collected by CCP1. Otherwise undercollateralisation occurs.

The importance of the trade flow structure can be highlighted by assuming that only one trader participates in CCP1. If so, the margins collected by CCP1 are exactly equal to the cross-CCP margin requirement of CCP2 because all margin requirements of CCP1 necessarily result from trades across CCPs. Thus, CCP1 is constantly undercollateralised as $\mu<\nu$. However, figure 3 illustrates that undercollateralisation can also occur in less extreme circumstances. In the given example, margins collected by the right-hand CCP are exactly sufficient to meet the cross-CCP margin requirement. Therefore, the right-hand CCP would be undercollateralised, if its margin requirement coefficient is smaller than that of the left-hand CCP.

In reality, CCPs may exclusively clear additional markets alongside the commonly cleared exchanges of the interoperability framework. Results established in this section do not change for the case of heterogenous market coverage. If CCPs apply the same risk management models, undercollateralisation will not occur. If CCPs apply different risk management models, the risk of undercollateralisation depends on trade flow patterns and on the extent to which CCP's margin requirement coefficients differ.

To summarise, a bilateral interoperability framework with CCPs applying different risk management models is prone to undercollateralisation. However, undercollateralisation does not necessarily have to occur if these risk management models are not too distinct and corresponding trade flow patterns are not too extreme. The larger the difference in the margin requirement coefficients, 
the more restricted the trade flow patterns compatible with sufficient collateralisation. Furthermore, trade flow patterns might allow for larger differences in coefficients the more participants CCPs have and the more equally these are distributed among CCPs. This is particularly relevant for emerging interoperability arrangements since an entering CCP might initially start with a limited number of participants.

\section{Multilateral interoperability}

This section analyses the risk of undercollateralisation in multilateral interoperability frameworks in which three or more CCPs participate. ${ }^{15}$

We consider the clearing of one security by three CCPs that apply identical margin requirements, i.e. $\mu=\nu=\lambda$. Let CCP1 clear for participants $1, \ldots, l$, CCP2 for participants $l+1, \ldots, l+m$ and CCP3 for participants $l+m+1, \ldots, l+$ $m+n$, where $l+m+n=k$. If multilateral netting is applied, CCP1 - for instance - requires the following margins from its members:

$$
\mu \sum_{i=1}^{l}\left|\sum_{j=1}^{k} x_{i, j}\right|
$$

Again, if we sum each CCPs' margin requirements, we find that a clearing system with several linked CCPs collects the same value of margins as a single CCP does.

CCP2 and CCP3 require CCP1 to deliver the following cross-CCP margins:

$$
\begin{gathered}
\nu\left|\sum_{i=1}^{l} \sum_{j=l+1}^{l+m} x_{i, j}\right| \\
\lambda\left|\sum_{i=1}^{l} \sum_{j=l+m+1}^{k} x_{i, j}\right|
\end{gathered}
$$

As $\mu=\nu=\lambda$, the condition for sufficient collateralisation of CCP1 is:

$$
\sum_{i=1}^{l}\left|\sum_{j=1}^{k} x_{i, j}\right| \stackrel{?}{\geq}\left|\sum_{i=1}^{l} \sum_{j=l+1}^{l+m} x_{i, j}\right|+\left|\sum_{i=1}^{l} \sum_{j=l+m+1}^{k} x_{i, j}\right|
$$

For CCP2 and CCP3 similar conditions can easily be derived. As in a bilateral framework, the cross-CCP net open positions for a pair of CCPs are also identical in a multilateral framework. However, in contrast to the bilateral framework, total cross-CCP margin requirements between CCPs in a multilateral framework are not identical. This is a consequence of the cross-CCP margin requirement being based on the sum of two cross-CCP net open positions that differ from CCP to CCP.

\footnotetext{
${ }^{15}$ Due to the linearity of the model, the same results apply to any arbitrary number of CCPS equal to or greater than three.
} 
We apply the following equality to show that the condition for sufficient collateralisation may be violated:

$$
\left|\sum_{i=1}^{l} \sum_{j=l+1}^{l+m} x_{i, j}+\sum_{i=1}^{l} \sum_{j=l+m+1}^{k} x_{i, j}\right|=\left|\sum_{i=1}^{l} \sum_{j=1}^{k} x_{i, j}\right|
$$

The left-hand side of expression 28 is the cross-CCP margin that CCP2 and CCP3 would require from CCP1 if CCP2 and CCP3 were merged. Equality 28 can be derived as a result of expression 1 .

According to the triangle inequality, the right-hand side of expression 28 is less than or equal to the left-hand side of condition 27, which represents the members' margins collection of CCP1. Given identical coefficients, this inequality says that a bilateral relationship - the merger of CCP2 and CCP3 - fulfils the condition for sufficient collateralisation. According to the triangle inequality, the right-hand side of equation 27 is greater than or equal to the left-hand side of condition 28. In other words, the cross-CCP net open position between CCP1 and the merged CCP2 and CCP3 is less than or equal to the sum of cross-CCP net open positions between CCP1 and separated CCP2 and CCP3. Combining these results yields the following expression:

$$
\sum_{i=1}^{l}\left|\sum_{j=1}^{k} x_{i, j}\right| \geq\left|\sum_{i=1}^{l} \sum_{j=l+1}^{k} x_{i, j}\right| \leq\left|\sum_{i=1}^{l} \sum_{j=l+1}^{l+m} x_{i, j}\right|+\left|\sum_{i=1}^{l} \sum_{j=l+m+1}^{k} x_{i, j}\right|
$$

Expression 29 shows that the condition of sufficient collateralisation as defined by expression 27 does not necessarily hold. Extending interoperability from a bilateral to a multilateral framework may result in cross-CCP margin requirements that violate the condition for sufficient collateralisation - even if CCPs apply identical margin coefficients. Unlike in a bilateral framework, traders in a multilateral framework may accumulate offsetting net open positions towards their own CCPs while their CCP's cross-CCP net open position does not offset. For instance, CCP1's traders can offset a long position towards CCP2 by a short position towards CCP3. As a result, CCP1's traders are flat towards their CCP while CCP1 has an exposure to CCP2 and CCP3. The inequality on the left-hand side of expression 29 illustrates that this does not happen if CCP2 and CCP3 were merged.

Figure 4 shows a multilateral framework with an undercollateralised CCP. Again, the net open position of a trader can easily be calculated as the absolute value of the number of arrows pointing towards a rectangle minus the number of arrows pointing away. The resulting margin requirements for traders are displayed as red numbers in the respective rectangles (since the calculation is still based on multilateral netting, the same numbers result as for a single CCP or for bilateral interoperability). The cross-CCP net open position between each pair of CCPs is calculated on the basis of bilateral netting (indicated as the green numbers closest to the respective CCP's ellipse). Summing the green numbers of a CCP results in the total cross-CCP margin requirement which a $\mathrm{CCP}$ must be able to cover in order to be sufficiently collateralised. Therefore, if the sum of traders' margin requirements (red numbers within an ellipse's rectangles) is greater than or equal to the sum of cross-CCP margin requirements (green numbers within an ellipse), a CCP is sufficiently collateralised. In figure 4, 
Figure 4: Example of a multilateral interoperability framework

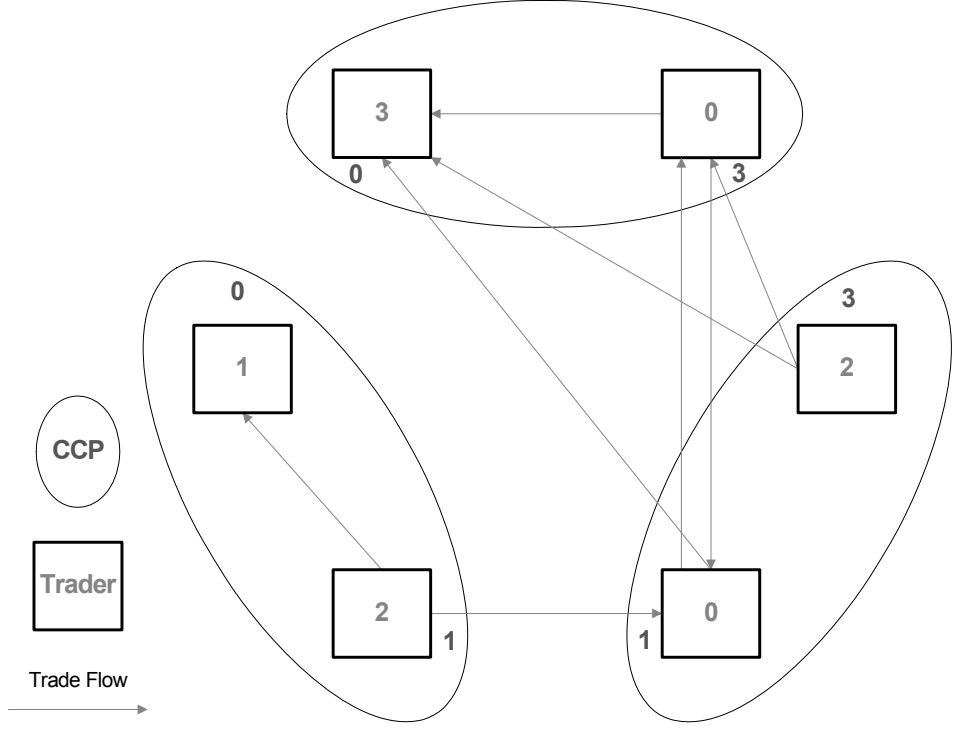

all but the right-hand CCP are sufficiently collateralised. The trader at the bottom of the right-hand CCP ellipse illustrates that in a multilateral framework a trader may accumulate offsetting net open positions towards its own CCP while its CCP's cross-CCP net open position does not offset. In our example, this trader faces a zero margin requirement while his trade pattern imposes a positive cross-CCP margin requirement on his CCP.

One could easily invent trade flows for which none, one, two or all CCPs end up undercollateralised. Thus, even if all CCPs apply the same margin requirement coefficients, $\mu=\nu=\lambda$, sufficient collateralisation in the currently applied rehypothecation model is not ensured if the interoperability arrangement involves more than two CCPs. This result generalises to any multilateral framework with an arbitrary number of CCPs greater than two. Because undercollateralisation even occurs with equal margin coefficients, we do not investigate a model with differing margin requirement coefficients.

To summarise, CCPs may find themselves in a paradoxical situation. Even though the sum of margins collected by CCPs equals the margins collected by a single CCP, margins may not suffice to collateralise cross-CCP exposures.

\section{Other rehypothecation models}

It is evident that the issue of undercollateralisation can not be circumvented by simply raising margin requirement coefficients. Even though more margins would be collected from traders - and CCPs are better protected from a participant's default - proportionately more collateral would also have to be delivered to the other CCPs. Therefore, the probability of undercollateralisation persists.

Regulators' solution to avoid undercollateralisation is straightforward. CCPs are expected to collect additional, specifically dedicated margins to cover cross- 
CCP exposures. Furthermore, CCPs are not allowed to use existing margins to cover cross-CCP exposures. Consequently, more collateral is needed to fulfil margin requirements.

Let us consider the example on bilateral interoperability in figure 3 . $4 \$$ of additional collateral are required to cover cross-CCP exposures (sum of green numbers). Thus, margin requirements for the clearing system sum up to $12 \$$ (the sum of red and green numbers). This is identical to the capital charges in the example on bilateral clearing in figure 1. Under the new guidelines, traders are indifferent between central clearing or bilateral clearing for the chosen example. Formally, bilateral interoperability is preferred to bilateral clearing if the following condition holds:

$$
\begin{aligned}
\nu\left|\sum_{i=1}^{l} \sum_{j=l+1}^{k} x_{i, j}\right| & +\mu\left|\sum_{i=l+1}^{k} \sum_{j=1}^{l} x_{i, j}\right| \leq \\
& \kappa \sum_{i=1}^{k} \sum_{j=1}^{k}\left|x_{i, j}\right|-\left(\mu \sum_{i=1}^{l}\left|\sum_{j=1}^{k} x_{i, j}\right|+\nu \sum_{i=l+1}^{k}\left|\sum_{j=1}^{k} x_{i, j}\right|\right)
\end{aligned}
$$

The left-hand side of inequality 30 denotes the additional margins required to fulfill regulators' new guidelines (being the sum of cross-CCP margin requirements), the right-hand side denotes the benefits from multilateral netting (being the difference between capital requirements under bilateral clearing and the sum of both CCPs margin requirements under bilateral interoperability). Thus, traders only prefer bilateral interoperability to bilateral clearing if the benefits from multilateral netting are large enough to compensate for the additional margins required by regulators. A similar condition can easily be derived for any multilateral interoperability framework.

Considering the example on multilateral interoperability in figure 4, regulators' guidelines result in $8 \$$ of additional margins to secure cross-CCP exposures (sum of green numbers). Thus, total margin requirements sum up to $16 \$$ (sum of red and green numbers). In comparison to multilateral interoperability with three CCPs, traders save $4 \$$ under bilateral clearing and $8 \$$ under a single CCP. Thus, for the given trade flow, netting benefits do not compensate for the additional margins required. Even bilateral clearing is preferred to multilateral interoperability.

Even though this is not generally true, the statement can be generalised by a simple thought experiment. Netting benefits are less likely to outweigh the costs of additional collateral as the number of CCPs in an interoperability framework increases. At the limit, $k$ traders are distributed over $k$ CCPs (each serving a single trader). This interoperability framework implies that all trades are crossCCP trades. As CCPs clear bilaterally, they face the same cross-CCP margin requirements as under bilateral clearing. Therefore, in addition to the CCPs' regular margin requirement based on multilateral netting, traders would have to provide additional collateral that, at the limit, equals the collateral requirement under bilateral clearing (assuming identical capital and margin requirement coefficients). Applying this setup to the trade flow of our example - assuming each trader is served by one CCP - traders have to meet margin requirements of $8 \$$ (multilateral netting through the CCP given as the sum of red numbers) plus an additional $12 \$$ to cover cross- $\mathrm{CCP}$ margin requirements (sum of red numbers 
in figure 1 on bilateral clearing).

For a single CCP, the left-hand side of inequality 30 equals zero by definition. Provided that the new guidelines become effective and assuming multilateral netting is beneficial (the right-hand side of inequality 30 is greater than zero), total margin requirements are minimised if there is a single CCP. Relative to the reference case of a single CCP, new guidelines lead to overcollateralisation, as they prohibit the reuse of exisiting margins. By contrast we argue that rehypothecated margins represent additional collateral because they change its' characteristic from a defaulter-pays instrument to a survivors-pay instrument. Consequently, we allow for the rehypothecation of members' margins and evaluate whether less collateral-intensive approaches may comply with regulators' guidelines of fully collateralised cross-CCP exposures. The next two subsections consider a scaleable margin model and a meta-CCP approach.

\subsection{Scaleable margin model}

To reduce excessive collateralisation in a multilateral interoperability framework, CCPs could ask for additional margins if and only if the sum of regular margins is insufficient to cover cross-CCP exposures. For this purpose, we derive a margin allocation rule that ensures sufficient collateralisation for any arbitrary number of interoperating CCPs by closing the collateral gap between margins collected and cross-CCP margin requirements.

For the sake of simplicity, we analyse the above defined multilateral interoperability case with $h=3$ CCPs. Let us define $\sum_{i=1}^{l} C M_{i}=\mu \sum_{i=1}^{l}\left|\sum_{j=1}^{k} x_{i, j}\right|$ as the sum of collected margins from CCP1's participants $i=1, \ldots, l$. Furthermore, $I M^{1}=\sum_{h=2}^{3} I M_{h}^{1}$ represents CCP1's cross CCP margin requirement, the sum of cross-CCP margin calls, $I M_{h}^{1}$, by CCP1's interoperating CCP2 and CCP3. Thus, CCP1 must meet the following condition to avoid undercollateralisation:

$$
\sum_{i=1}^{l} C M_{i} \geq I M^{1}
$$

If inequality 31 does not hold, CCP1 calls for additional margins from its members by applying the following allocation rule:

$$
A M_{i}=\left(I M^{1}-\sum_{i=1}^{l} C M_{i}\right) \frac{C M_{i}}{\sum_{i=1}^{l} C M_{i}}+C M_{i}
$$

$A M_{i}$ denotes the adjusted margin requirement that each trader $i$ has to meet in order for CCP1 to avoid undercollateralisation. The first term of the right-hand side represents the gap between cross-CCP margins required and the margins collected from members. The gap is multiplied by the allocation rule, which is simply trader $i$ 's share in the sum of collected margins. As proposed, this could either be a real-time measure of a trader's share in margins or an average share over a predetermined period of the past. Because some participants might regularly be flat, ${ }^{16}$ a $\mathrm{CCP}$ can alternatively base the allocation rule on the traders' share in the gross position. The last term is the usual margin requirement that a trader has to meet. It is easy to see that summing the adjusted

\footnotetext{
${ }^{16}$ For instance, algorithmic traders usually end the trading day flat.
} 
margin requirements over all traders of $\mathrm{CCP} 1$ results in the sum of cross-CCP margin calls for CCP1:

$$
\sum_{i=1}^{l} A M_{i}=I M^{1}=\nu\left|\sum_{i=1}^{l} \sum_{j=l+1}^{m} x_{i, j}\right|+\lambda\left|\sum_{i=l}^{l} \sum_{j=l+m+1}^{k} x_{i, j}\right|
$$

To avoid undercollateralisation, we determine the effective margin requirement for trader $i$ as follows:

$$
M_{i}=\max \left\{C M_{i}, A M_{i}\right\}
$$

Excessive collateralisation can be reduced since additional collateral is collected only to close the gap between margins collected and cross-CCP margin requirements. As can easily be seen from the example in figure 4 , the undercollateralised CCP on the right-hand side would have to collect $\$ 2$ of additional margins. Therefore, the clearing system requires $\$ 6$ less than under the new risk management model imposed by regulators' new guidelines and $\$ 2$ less than under bilateral clearing. In our example, the scaleable margin model is more costly than a single CCP approach, but is able to restore incentives to clear through interoperating CCPs rather than via a bilateral clearing framework.

This is generally true and can be formalised by comparing equation 33 with the capital requirements of a bilateral clearing system:

$$
\nu\left|\sum_{i=1}^{l} \sum_{j=l+1}^{m} x_{i, j}\right|+\lambda\left|\sum_{i=l}^{l} \sum_{j=l+m+1}^{k} x_{i, j}\right| \leq \kappa \sum_{i=1}^{l} \sum_{j=1}^{k}\left|x_{i, j}\right|
$$

Expression 35 illustrates that CCP1's margin requirement under interoperability is less than or equal to the capital requirements under bilateral clearing with participants $i=1, \ldots l$. The inequality certainly holds true if $\kappa \geq \mu, \nu, \lambda$ but may - depending on the multilateral netting effect - be valid for a lower value of $\kappa$. We can further expand the result of expression 35 to each individual CCP of the interoperability framework. Ultimately, the entire clearing system is better off when moving from bilateral clearing to an interoperability framework with adjusted margin requirements. Due to linearity, the result can be generalised to any arbitrary number of CCPs participating in a multilateral interoperability framework. Thus, in terms of margin requirements multilateral interoperability is preferred to bilateral clearing.

Additionally, we can show that a single CCP is more beneficial than the interoperability framework in terms of margin requirements. Summing up expression 32 over all traders and CCPs and comparing the result with the margin requirement of a single $\mathrm{CCP}$ on the left hand side of inequality 36 we obtain:

$$
\mu \sum_{i=1}^{k}\left|\sum_{j=1}^{k} x_{i, j}\right| \leq \sum_{h=1}^{3} I M^{h}
$$

Expression 36 says that the sum of margin requirements of a single CCP is less than or equal to the sum of cross-CCP margin requirements of the interoperability framework which is the upper-bound of margin requirements for traders under the new guidelines.

The scaleable margin model can be used for bilateral as well as for multilateral frameworks. Additionally, differences in cross-CCP risk management 
models do not require harmonisation of individual risk management models. However, sufficient collateralisation is ensured if and only if all interoperating CCPs apply the scaleable margin model.

\subsection{Meta-CCP}

Undercollateralisation in a multilateral framework occurs, because cross-CCP exposures are not linked to the exposures between members and the CCP. A way to mitigate the risk of undercollateralisation is to re-establish this linkage, i.e. to collapse a multilateral framework into a bilateral one. For this purpose, we introduce the concept of a meta-CCP, i.e. a CCP for CCPs. The intuition is simple. A meta-CCP reduces multilateral relationships between CCPs into bilateral relationships between CCPs and the meta-CCP (essentially, this is the same as what a CCP does for its participants).

Again, without loss of generality, we concentrate our attention to the multilateral interoperability framework with three CCPs and analyse the case of CCP1 only. We assume that all CCPs apply identical margin requirement coefficients, $\mu=\nu=\lambda$, and, for the sake of simplicity, we omit them. Margins collected by CCP1 from its traders equal:

$$
M_{1}=\sum_{i=1}^{l}\left|\sum_{j=1}^{k} x_{i, j}\right|
$$

In contrast to a framework without a meta-CCP, the meta-CCP does not have to account for bilateral exposures between CCPs, but can multilaterally net cross-CCP exposures. The multilateral net open position of a CCP towards the meta-CCP is defined as the absolute value of the sum of total multilateral net open positions that traders of a CCP have towards traders of all interoperating CCPs. For instance, CCP1 has the following exposure towards the meta-CCP:

$$
M C C P_{1}=\left|\sum_{i=1}^{l} \sum_{j=l+1}^{k} x_{i, j}\right|
$$

As we omit identical margin coefficients, exposures equal margins. To compare resulting margin requirements, we define $C M^{1}$ as the cross-CCP margin requirements of CCP2 and CCP3 towards CCP1:

$$
C M^{1}=\left|\sum_{i=1}^{l} \sum_{j=l+1}^{l+m} x_{i, j}\right|+\left|\sum_{i=1}^{l} \sum_{j=l+m+1}^{k} x_{i, j}\right|
$$

Applying the triangle inequality to expressions 38 and 39, we find that the margin requirement of the meta-CCP is lower than or equal to the sum of requirements by interoperating CCPs:

$$
M C C P_{1} \leq C M^{1}
$$

Multilateral netting by a meta-CCP collapses cross-CCP margin requirements into the requirement of a merged CCP2 and CCP3 (as denoted in expression 29). 
To investigate whether the margin requirements of the meta-CCP are sufficiently collateralised, we derive the condition for sufficient collateralisation by combining expressions 37 and 38 :

$$
M_{1}=\sum_{i=1}^{l}\left|\sum_{j=1}^{k} x_{i, j}\right| \stackrel{?}{\geq}\left|\sum_{i=1}^{l} \sum_{j=l+1}^{k} x_{i, j}\right|=M C C P_{1}
$$

Again, by applying expression 1, the right-hand side of inequality 41 can be extended as follows:

$$
\left|\sum_{i=1}^{l} \sum_{j=l+1}^{k} x_{i, j}\right|=\left|\sum_{i=1}^{l} \sum_{j=1}^{k} x_{i, j}\right|
$$

Indeed, the triangle inequality confirms that sufficient collateralisation is ensured if CCP1 simply rehypothecates its collected margins towards the MetaCCP. The same result can be derived for all three CCPs.

Figure 5: Example of a multilateral interoperability framework with a meta$\mathrm{CCP}$

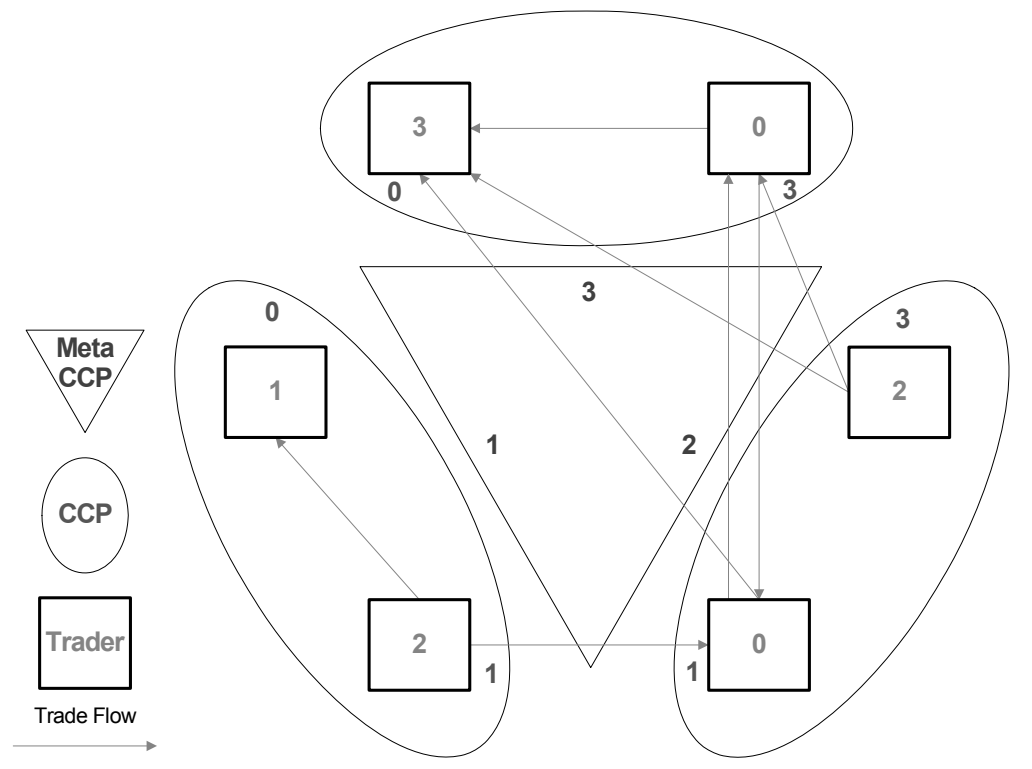

Identical margin requirement coefficients are not a prerequisite for ensuring sufficient collateralisation. As we can derive from the analysis of bilateral interoperability in section 4 , the sufficient condition for avoiding undercollateralisation is that the meta-CCP's margin requirement coefficient must be less than or equal to any of the CCPs' margin requirement coefficients. Again, this is not a necessary condition. If trade flows are not too adverse, a slightly greater margin coefficient for the meta-CCP might still be compatible with sufficient collateralisation.

The establishment of a meta-CCP enables CCPs to avoid undercollateralisation in a multilateral framework without requiring any additional margin. A meta-CCP reintroduces the bilateral relationship that links cross-CCP margins 
to members' margins. In other words, multilateral netting between CCPs must always result in multilateral net open positions between the meta-CCP and its CCPs that are less than or equal to the regular margins collected by CCPs.

Figure 5 illustrates a clearing system with a multilateral interoperability framework secured by a meta-CCP (represented by the triangle). CCPs now cover their cross-CCP exposures via the meta-CCP, which allows them to net their cross-CCP positions on a multilateral basis. The blue numbers in the triangle denote the margin requirements of the meta-CCP towards the CCPs. Sufficient collateralisation is ensured if the sum of red numbers in an ellipse is greater than or equal to the blue number closest to the respective ellipse. As predicted by the model, all CCPs collect sufficient margins from their members to cover the meta-CCP's margin requirement. In particular, while the righthand CCP still collects $\$ 2$ from its members, it also has to deliver exactly $\$ 2$ as cross-CCP margin to the meta-CCP (instead of $\$ 4$ without a meta-CCP, i.e. the sum of green numbers).

\section{Conclusions}

Similar to Duffie and Zhu (2011), we find that a fragmented clearing system with multiple CCPs is inefficient. Going beyond their findings, we illustrate that interoperability resolves the inefficiencies associated with fragmentation. In particular, interoperability enables traders to multilaterally net their positions across all CCPs. This minimises margin requirements and counterparty exposures in the clearing system.

The paper is inspired by recent efforts on the part of some European CCPs to establish multilateral interoperability in European cash equity markets. CCPs proposed that the existing bilateral cross-CCP risk management model also be applied to forthcoming multilateral interoperability arrangements. In this model, CCPs cover exposures via rehypothecated margins that are collected from participants. We analyse the rehypothecation model and demonstrate that collateralisation in a bilateral framework suffices as long as CCPs' margin requirements are not too distinct. However, multilateral interoperability arrangements are generally prone to undercollateralisation. Therefore, we confirm regulators' concerns about systemic risk.

Moreover, we analyse regulators' recently issued guidelines on interoperability arrangements to contain systemic risks. They effectively eliminate contagion insofar as sufficient collateralisation is ensured. However, because regulators require additional collateral on top of the existing financial resources, they do so at a cost of an overcollateralised clearing system. Considering that CCPs all over Europe collect several billion euros as margin in cash equity markets, overcollateralisation is not only of commercial relevance but might also have a wider economic impact by increasing the opportunity cost of collateral and the transaction costs of clearing. Heller and Vause (2011) and Singh (2010) provide evidence for OTC derivatives that supports this view. As a reaction, traders may try to bypass CCPs and, in so doing, reintroduce fragmentation - which increases the clearing system's overall exposure - or reduce trading that allows to reallocate risks more efficiently.

With regard to the G-20 commitment towards mandatory clearing of OTC derivatives, Duffie, Li and Lubke (2010) assume that the market structure of 
the OTC derivatives clearing system will be fragmented. Furthermore, the integration of local markets and access for small and mid-tier market participants emerge as serious concerns among remote markets such as, for instance, Australia and Canada. ${ }^{17}$ Fragmentation and limited access for global CCPs will inevitably lead to tiering, i.e. access of smaller participants through larger participants. However, tiering may be subject to further concerns such as inefficient market outcomes. Moreover, tiering countervails the G-20's overall target to strengthen financial stability by mandatory clearing because it concentrates risks at a few large participants and, consequently, amplifies the too-big-to-fail problem. A clearing system of interoperating local and global CCPs may help to resolve these issues. However, significant efforts are required to establish and operate safe and efficient interoperability arrangements.

We introduce two cross-CCP risk management models that either reduce or eliminate undercollateralisation while reducing or avoiding overcollateralisation. Whereas the 'scaleable margin model' is easy to implement, it does require extra collateral to avoid undercollateralisation, although to a lesser extent than imposed by regulators. We illustrate that the clearing system can go a step further in reducing collateral requirements by introducing a CCP for CCPs. Under certain conditions this 'meta-CCP' allows sufficient collateralisation to be ensured without requiring any extra collateral. Although the establishment of a meta-CCP may be difficult due to the complexity of its risk management and the commercial, regulatory and political concerns, it may be worthwhile to further explore its feasibility.

\section{References}

[1] Australian Prudential Regulation Authority, Australian Securities \& Investment Commission and Reserve Bank of Australia. 2009. Survey of the OTC Derivatives Market in Australia. ISBN: 978-0-9805857-4-2. Online.

[2] Basel Committee on Banking Supervision. 2009. Strengthening the Resilience of the Banking Sector. Bank for International Settlements Consultative Document.

[3] Bates, David and Roger Craine. 1999. Valuing the Futures Market Clearinghouse's Default Exposure during the 1987 Crash. Journal of Money, Credit, and Banking, Vol. 31 (2), p. 248-72.

[4] Bernanke, Ben. 1990. Clearing and Settlement during the Crash. The Review of Financial Studies, Volume 3, Number 1, p.133-151.

[5] Canadian OTC Derivatives Working Group. 2010. Reform of Over-theCounter (OTC) Derivatives Markets in Canada: Discussion Paper from the Canadian OTC Derivatives Working Group. Online.

[6] Committee on Payment and Settlement Systems. 2003. A glossary of terms used in payments and settlement systems. Bank for International Settlements.

\footnotetext{
${ }^{17}$ See Australian Prudential Regulation Authority etal. (2009) and Canadian OTC Derivatives Working Group (2010).
} 
[7] Committee on Payment and Settlement Systems and Technical Committee of the International Organization of Securities Commissions. 2004. Recommendations for Central Counterparties. Bank for International Settlements. No 64. November 2004.

[8] Duffie, Darrell and Haoxiang Zhu. 2011. Does a Central Clearing Counterparty reduce Counterparty Risk?. Review of Asset Pricing Studies 00(0).

[9] Duffie, Darrell, Ada Li and Theo Lubke. 2010. Policy Perspectives on OTC Derivatives Market Infrastructure. Federal Reserve Bank of New York. Staff Reports No. 424.

[10] European Commission, Internal Market and Services DG, Financial Services Policy and Financial Markets, Financial Markets Infrastructure (2009). The Code of Conduct on Clearing and Settlement: Three Years of Experience. Online.

[11] Gemmill, Gordon. 1994. Margins and the Safety of Clearing Houses. Journal of Banking and Finance. Vol. 18 (5). p 979-96

[12] Gibson, Rajna and Carsten Murawski. 2008. The Price of Protection: Derivatives: Default Risk, and Margining. Swiss Finance Institute Research Paper. No. 08-43.

[13] Hardouvelis, Gikas A. and Dongcheol Kim. 1995. Margin Requirements, Price Fluctuations, and Market Participation in Metal Futures. Journal of Money, Credit, and Banking. Vol. 27 (3), p. 659-71.

[14] Hartzmark, Michael L.. 1986. The Effects of Changing Margin Levels on Futures Market Activity, the Composition of Traders in the Market, and Price Performance. Journal of Business. Vol. 59 (2). p. S147-80.

[15] Haene, Philipp and Andy Sturm. 2009. Optimal Central Counterparty Risk Management. Swiss National Bank Working Papers 2009-7.

[16] Heller, Daniel and Nicholas Vause. 2011. A quantification of the financial resources needed to expand central clearing. BIS Working Papers. Forthcoming.

[17] Kahn, Charles and William Roberds. 1998. Payment System Settlement and Bank Incentives. The Review of Financial Studies 11(4), 845-870.

[18] Knott, Raymond and Alastair Mills. 2002. Modeling Risk in Central Counterparty Clearing Houses: A Review. Financial Stability Review, Bank of England, p. 162-173.

[19] Koeppl, Thorsten and Cyril Monnet. 2009. Collateral Policies for Central Counterparties. Mimeo.

[20] Koeppl, Thorsten and Cyril Monnet. 2010. The Emergence and Future of Central Counterparties. Queen's University Economics Departement Working Paper No. 1241.

[21] Koeppl, Thorsten, Cyril Monnet and Ted Temzelides. 2009. Optimal Clearing Arrangements for Financial Trades. Mimeo. 
[22] Kraenzlin, Sébastien and Benedikt von Scarpatetti. 2010. Liasions and Scheming: The Network of the Swiss Franc Repo Market. Mimeo. Swiss National Bank and University of Basel.

[23] Kupiec, Paul. 1994. The Performance of S\&P 500 Futures Product Margins under the SPAN Margining System. Journal of Futures Markets. Vol. 14 (7). p 789-811.

[24] Kupiec, Paul and Patricia White. 1996. Regulatory Competition and the Efficiency of alternative Derivative Product Margining Systems. Journal of Futures Markets. Vol. 16 (8). pp. 943-68.

[25] Pirrong, Craig. 2009. The Economics of Clearing in Derivatives Markets: Netting, Asymmetric Information, and the Sharing of Default Risk through a Central Counterparty. University of Houston, Mimeo.

[26] Shanker, Latha and Narayanaswamy Balakrishnan. 2005. Optimal Clearing Margin, Capital and Price Limits for Futures Clearinghouses. Journal of Banking and Finance. Vol. 29 (7). p. 1611-30.

[27] Singh, Manmohan. 2010. Collateral, Netting and Systemic Risk in the OTC Derivatives Market. IMF Working Paper, WP/10/99.

\section{Appendix}

The appendix briefly introduces the relevant CPSS/IOSCO recommendations. In the first subsection we illustrate a CCP's generic risk management model. Further we discuss interoperability arrangements. Finally, we present the new guidelines issued by Dutch, Swiss and UK authorities.

\section{A central counterparty}

A CCP is an entity that interposes itself between the seller and the buyer of a financial contract. The original contract is replaced by two new ones, one between the CCP and the seller and one between the CCP and the buyer. Essentially, the CCP becomes the new counterparty of the seller and the buyer. A CCP typically guarantees the fulfilment of the new contracts to its participants even if one of them fails to meet its obligations. As a result, a CCP concentrates credit risks. In cash equity markets, principal risk is usually mitigated via a delivery-versus-payment (DvP) mechanism. However, the replacement cost risk - which is the potential loss from replacing open contracts of a defaulting participant - remains on the books of the CCP. ${ }^{18}$

Given the specific role CCPs play in financial markets, they are typically regulated entities. In particular, a CCP is required to collect financial resources to cover potential losses that may result from a defaulting participant. Regulatory requirements are outlined in the report on Recommendations for Central Counterparties (RCCPs), and represents international minimum requirements. ${ }^{19}$ With respect to financial resources, CCPs have to meet the following two recommendations:

${ }^{18} \mathrm{DvP}$ is a mechanism in an exchange-for-value settlement system that ensures that the final transfer of one asset occurs if and only if the final transfer of another asset occurs. See CPSS (2003).

${ }^{19}$ RCCPs are commonly issued by the CPSS/IOSCO (2004). 
- Margin requirements (Recommendation 4): "If a CCP relies on margin requirements to limit its credit exposures to participants, those requirements should be sufficient to cover potential exposures in normal market conditions. [...]";

- Financial resources (Recommendation 5): "A CCP should maintain sufficient financial resources to withstand, at a minimum, a default by the participant to which it has the largest exposure in extreme but plausible market conditions.";

Whereas margin requirements are usually designed to cope with normal price movements, other financial resources should be available to cope with tail events, i.e. extreme price movements. To meet these requirements, CCPs usually apply various lines of defence, which can broadly be grouped according to two principles:

- Defaulter-pays principle: Typically, potential losses of a CCP are covered via prefunded financial resources of the defaulting participant; ${ }^{20}$

- Survivors-pay principle: Survivors-pay instruments cover financial losses via financial resources of the surviving participants. In contrast to a defaulter-pays instrument, a survivors-pay instrument is a loss-sharing agreement between non-defaulting participants. ${ }^{21}$

CCPs predetermine the order in which financial resources will be used to cover losses. Usually, CCPs only fall back on the default fund contributions if the resources of the defaulting member do not cover losses. A CCP's reserves and own capital may be understood as the ultimate line of defence. Finally, surviving participants are sometimes required to replenish the default fund after a CCP has experienced a loss. ${ }^{22}$

\section{B Interoperability}

Interoperability arrangements interconnect CCPs by enabling participants of one CCP to clear trades with participants of another CCP. Thus, a CCP interposes itself between trades of its own participants and those of participants from an interoperating CCP. Therefore, exposures result between the buyer and its CCP, the seller and its CCP and, as a particular feature of interoperability, across CCPs if a buyer and a seller do not participate in the same CCP. Participants benefit from interoperability in two ways. First, a participant can access different trading platforms without necessarily being a member of several CCPs. Second, margin requirements are reduced because of the enhanced netting opportunities of trading positions being cleared through one CCP only. With regard to the clearing system as a whole, interoperability may reduce overall risks due to the netting of a larger set of trading positions.

\footnotetext{
${ }^{20}$ Defaulter-pays instruments are typically represented by the margins that a CCP collects from its members. Margin requirements normally depend on the participant's current exposure and are usually intended to cover losses that would occur under normal market conditions.

${ }^{21}$ Usually, participants are required to prefund a collective default fund. The size of the default fund contribution typically depends on the size of a participant's average exposure over a certain period of time.

${ }^{22}$ For further explanations of the different lines of defence of a CCP see Duffie, Li and Lubke (2010). The optimal balance of lines of defence is analysed in Haene and Sturm (2009).
} 
Regulatory authorities explicitly consider interoperability in the CPSS/IOSCO report on RCCPs in 2004:

- Risks of links between CCPs (Recommendation 11): "CCPs that establish links either cross-border or domestically to clear trades should evaluate the potential sources of risks that can arise, and ensure that the risks are managed prudently on an ongoing basis [...]";

This recommendation is not very specific in addressing cross-CCP risk management. In particular, the exchange of financial resources to collateralise crossCCP exposures is hardly discussed. Further, it only addresses bilateral interoperability frameworks - i.e. arrangements involving two interoperating CCPs - but does not consider multilateral interoperability.

\section{New guidelines}

In existing bilateral interoperability frameworks, exposures between CCPs are covered by rehypothecating members' margins. This raises the question whether participants' margins collected by a CCP are sufficient to cover its exposures vis-à-vis its interoperating CCPs. Even though a CCP's default may be qualified as a rare event, as Bernanke (1990) points out, only rumours of a CCP's potential default can have devastating effects on market confidence and trading. Worse, if many CCPs are linked via multiple interoperability frameworks, the whole clearing and trading system could potentially be affected. As a CCP's own capital may be far lower than its cross-CCP exposures the default of an interoperating CCP may result in contagion if the network of CCPs is subject to undercollateralisation.

Recently, Dutch, Swiss and UK regulators delayed interoperability initiatives by the European Multilateral Clearing Facility (NL), EuroCCP (UK), LCH.Clearnet Ltd. (UK) and SIX x-clear (CH). Regulators released common guidelines with respect to the management of cross-CCP exposures. Essentially, $\mathrm{RCCP} 11$ was amended by the following four criteria:

1. CCPs are required to fully collateralise cross-CCP exposures;

2. CCPs are required to collect additional resources to cover cross-CCP exposures. These resources are expected to be collected on top of participant's regular lines of defence;

3. Such extra collateral for cross-CCP exposures must be held in a prefunded manner;

4. Interoperability frameworks must be scaleable, i.e. the safety of an interoperability arrangement must not be negatively affected by a change in the number of participating CCPs.

The term 'full collateralisation' refers to cross-CCP margins that must be determined in accordance with the requirements for ordinary members.

The second guideline requires CCPs to provide additional collateral on top of the collected financial resources that cover members' exposures towards their $\mathrm{CCP}$. The guideline aims to prevent CCPs from rehypothecating existing margins or default fund contributions of their participants. In particular, regulators 
require additional financial resources as they suspect undercollateralisation or a weakening of CCPs' lines of defence if CCPs simply rehypothecate existing financial resources. Thus, CCPs' current cross-CCP risk management model does not comply with the second guideline.

The third guideline attempts to eliminate wrong-way risks. To do so, regulators require financial resources covering cross-CCP exposures to be prefunded. Therefore, financial resources such as bank guarantees or insurances are not eligible. Because the availability of such resources crucially depends on the liquidity and solvency of the guarantor or insurer, the resources may not be available when needed.

With scalability, regulators require cross-CCP risk management models to also ensure sufficient collateralisation if additional CCPs join or if participating CCPs quit the interoperability framework. Alternatively scalability might be considered as a matter of contestability, i.e. a sound risk management model must not deter potential entrants from joining a framework. ${ }^{23}$

Regulators' guidelines are forcing CCPs to adjust the currently applied crossCCP risk management model. To comply with the first two guidelines, CCPs will refrain from rehypothecating members' existing margins but will rehypothecate additional margin collected from their members on top of the regular margin contributions. In essence, participants will have to 'double-collateralise' exposures that result from trades across CCPs.

Generally, we can distinguish three different types of prefunded financial resources that can be exchanged to cover cross-CCP exposures. These are: members' default fund contributions, own capital (including retained earnings) and members' margin contributions. The mutual exchange of the first two financial resources reduces a CCP's ability to withstand a participant's default. If these financial resources were rehypothecated to the other CCPs, they could not be used by the CCP that incurs a participant's default. Thus, the CCP's has fewer financial resources available to cover potential losses. Therefore, it is meaningful to refrain from mutually exchanging default fund contributions and own financial resources to cover cross-CCP exposures.

In contrast, the mutual exchange of margins as a defaulter-pays instrument does not reduce a CCP's ability to withstand a participant's default since by definition - only those margins that stem from the defaulting participant can be used to cover potential losses. Margins of surviving members remain untouched since they must be reimbursed to surviving members in case of a CCP's default. Indeed, the rehypothecation of participants' margins towards interoperating CCPs changes the original character of margins from a defaulter-pays instrument to a survivors-pay instrument. A CCP's default enables surviving CCPs to use rehypothecated margins of the defaulting CCPs' members to cover the losses. Thus, the surviving participants of a defaulting CCP can experience a loss up to the full amount of their regular margin contributions, which would not be the case if they were not rehypothecated. Consequently, rehypothecated regular margin contributions actually become additional collateral for the surviving CCPs.

\footnotetext{
${ }^{23}$ Since we focus on cross-CCP risk management, we do not further discuss the interrelationship between risk management and contestability.
} 


\section{Swiss National Bank Working Papers published since 2004:}

2004-1 Samuel Reynard: Financial Market Participation and the Apparent Instability of Money Demand

2004-2 Urs W. Birchler and Diana Hancock: What Does the Yield on Subordinated Bank Debt Measure?

2005-1 Hasan Bakhshi, Hashmat Khan and Barbara Rudolf: The Phillips curve under state-dependent pricing

2005-2 Andreas M. Fischer: On the Inadequacy of Newswire Reports for Empirical Research on Foreign Exchange Interventions

2006-1 Andreas M. Fischer: Measuring Income Elasticity for Swiss Money Demand: What do the Cantons say about Financial Innovation?

2006-2 Charlotte Christiansen and Angelo Ranaldo: Realized Bond-Stock Correlation: Macroeconomic Announcement Effects

2006-3 Martin Brown and Christian Zehnder: Credit Reporting, Relationship Banking, and Loan Repayment

2006-4 Hansjörg Lehmann and Michael Manz: The Exposure of Swiss Banks to Macroeconomic Shocks - an Empirical Investigation

2006-5 Katrin Assenmacher-Wesche and Stefan Gerlach: Money Growth, Output Gaps and Inflation at Low and High Frequency: Spectral Estimates for Switzerland

2006-6 Marlene Amstad and Andreas M. Fischer: Time-Varying Pass-Through from Import Prices to Consumer Prices: Evidence from an Event Study with Real-Time Data

2006-7 Samuel Reynard: Money and the Great Disinflation

2006-8 Urs W. Birchler and Matteo Facchinetti: Can bank supervisors rely on market data? A critical assessment from a Swiss perspective

2006-9 Petra Gerlach-Kristen: A Two-Pillar Phillips Curve for Switzerland

2006-10 Kevin J. Fox and Mathias Zurlinden: On Understanding Sources of Growth and Output Gaps for Switzerland

2006-11 Angelo Ranaldo: Intraday Market Dynamics Around Public Information Arrivals

2007-1 Andreas M. Fischer, Gulzina Isakova and Ulan Termechikov: Do FX traders in Bishkek have similar perceptions to their London colleagues? Survey evidence of market practitioners' views 
2007-2 Ibrahim Chowdhury and Andreas Schabert: Federal Reserve Policy viewed through a Money Supply Lens

2007-3 Angelo Ranaldo: Segmentation and Time-of-Day Patterns in Foreign Exchange Markets

2007-4 Jürg M. Blum: Why ‘Basel II’ May Need a Leverage Ratio Restriction

2007-5 Samuel Reynard: Maintaining Low Inflation: Money, Interest Rates, and Policy Stance

2007-6 Rina Rosenblatt-Wisch: Loss Aversion in Aggregate Macroeconomic Time Series

2007-7 Martin Brown, Maria Rueda Maurer, Tamara Pak and Nurlanbek Tynaev: Banking Sector Reform and Interest Rates in Transition Economies: Bank-Level Evidence from Kyrgyzstan

2007-8 Hans-Jürg Büttler: An Orthogonal Polynomial Approach to Estimate the Term Structure of Interest Rates

2007-9 Raphael Auer: The Colonial Origins Of Comparative Development: Comment. A Solution to the Settler Mortality Debate

2007-10 Franziska Bignasca and Enzo Rossi: Applying the Hirose-Kamada filter to Swiss data: Output gap and exchange rate pass-through estimates

2007-11 Angelo Ranaldo and Enzo Rossi: The reaction of asset markets to Swiss National Bank communication

2007-12 Lukas Burkhard and Andreas M. Fischer: Communicating Policy Options at the Zero Bound

2007-13 Katrin Assenmacher-Wesche, Stefan Gerlach, and Toshitaka Sekine: Monetary Factors and Inflation in Japan

2007-14 Jean-Marc Natal and Nicolas Stoffels: Globalization, markups and the natural rate of interest

2007-15 Martin Brown, Tullio Jappelli and Marco Pagano: Information Sharing and Credit: Firm-Level Evidence from Transition Countries

2007-16 Andreas M. Fischer, Matthias Lutz and Manuel Wälti: Who Prices Locally? Survey Evidence of Swiss Exporters

2007-17 Angelo Ranaldo and Paul Söderlind: Safe Haven Currencies 
2008-1 Martin Brown and Christian Zehnder: The Emergence of Information Sharing in Credit Markets

2008-2 Yvan Lengwiler and Carlos Lenz: Intelligible Factors for the Yield Curve

2008-3 Katrin Assenmacher-Wesche and M. Hashem Pesaran: Forecasting the Swiss Economy Using VECX* Models: An Exercise in Forecast Combination Across Models and Observation Windows

2008-4 Maria Clara Rueda Maurer: Foreign bank entry, institutional development and credit access: firm-level evidence from 22 transition countries

2008-5 Marlene Amstad and Andreas M. Fischer: Are Weekly Inflation Forecasts Informative?

2008-6 Raphael Auer and Thomas Chaney: Cost Pass Through in a Competitive Model of Pricing-to-Market

2008-7 Martin Brown, Armin Falk and Ernst Fehr: Competition and Relational Contracts: The Role of Unemployment as a Disciplinary Device

2008-8 Raphael Auer: The Colonial and Geographic Origins of Comparative Development

2008-9 Andreas M. Fischer and Angelo Ranaldo: Does FOMC News Increase Global FX Trading?

2008-10 Charlotte Christiansen and Angelo Ranaldo: Extreme Coexceedances in New EU Member States' Stock Markets

2008-11 Barbara Rudolf and Mathias Zurlinden: Measuring capital stocks and capital services in Switzerland

2008-12 Philip Sauré: How to Use Industrial Policy to Sustain Trade Agreements

2008-13 Thomas Bolli and Mathias Zurlinden: Measuring growth of labour quality and the quality-adjusted unemployment rate in Switzerland

2008-14 Samuel Reynard: What Drives the Swiss Franc?

2008-15 Daniel Kaufmann: Price-Setting Behaviour in Switzerland - Evidence from CPI Micro Data

2008-16 Katrin Assenmacher-Wesche and Stefan Gerlach: Financial Structure and the Impact of Monetary Policy on Asset Prices

2008-17 Ernst Fehr, Martin Brown and Christian Zehnder: On Reputation: A Microfoundation of Contract Enforcement and Price Rigidity 
2008-18 Raphael Auer and Andreas M. Fischer: The Effect of Low-Wage Import Competition on U.S. Inflationary Pressure

2008-19 Christian Beer, Steven Ongena and Marcel Peter: Borrowing in Foreign Currency: Austrian Households as Carry Traders

2009-1 Thomas Bolli and Mathias Zurlinden: Measurement of labor quality growth caused by unobservable characteristics

2009-2 Martin Brown, Steven Ongena and Pinar Yeșin: Foreign Currency Borrowing by Small Firms

2009-3 Matteo Bonato, Massimiliano Caporin and Angelo Ranaldo: Forecasting realized (co)variances with a block structure Wishart autoregressive model

2009-4 Paul Söderlind: Inflation Risk Premia and Survey Evidence on Macroeconomic Uncertainty

2009-5 Christian Hott: Explaining House Price Fluctuations

2009-6 Sarah M. Lein and Eva Köberl: Capacity Utilisation, Constraints and Price Adjustments under the Microscope

2009-7 Philipp Haene and Andy Sturm: Optimal Central Counterparty Risk Management

2009-8 Christian Hott: Banks and Real Estate Prices

2009-9 Terhi Jokipii and Alistair Milne: Bank Capital Buffer and Risk Adjustment Decisions

2009-10 Philip Sauré: Bounded Love of Variety and Patterns of Trade

2009-11 Nicole Allenspach: Banking and Transparency: Is More Information Always Better?

2009-12 Philip Sauré and Hosny Zoabi: Effects of Trade on Female Labor Force Participation

2009-13 Barbara Rudolf and Mathias Zurlinden: Productivity and economic growth in Switzerland 1991-2005

2009-14 Sébastien Kraenzlin and Martin Schlegel: Bidding Behavior in the SNB's Repo Auctions

2009-15 Martin Schlegel and Sébastien Kraenzlin: Demand for Reserves and the Central Bank's Management of Interest Rates

2009-16 Carlos Lenz and Marcel Savioz: Monetary determinants of the Swiss franc 
2010-1 Charlotte Christiansen, Angelo Ranaldo and Paul Söderlind: The Time-Varying Systematic Risk of Carry Trade Strategies

2010-2 Daniel Kaufmann: The Timing of Price Changes and the Role of Heterogeneity

2010-3 Loriano Mancini, Angelo Ranaldo and Jan Wrampelmeyer: Liquidity in the Foreign Exchange Market: Measurement, Commonality, and Risk Premiums

2010-4 Samuel Reynard and Andreas Schabert: Modeling Monetary Policy

2010-5 Pierre Monnin and Terhi Jokipii: The Impact of Banking Sector Stability on the Real Economy

2010-6 Sébastien Kraenzlin and Thomas Nellen: Daytime is money

2010-7 Philip Sauré: Overreporting Oil Reserves

2010-8 Elizabeth Steiner: Estimating a stock-flow model for the Swiss housing market

2010-9 Martin Brown, Steven Ongena, Alexander Popov, and Pinar Yeșin: Who Needs Credit and Who Gets Credit in Eastern Europe?

2010-10 Jean-Pierre Danthine and André Kurmann: The Business Cycle Implications of Reciprocity in Labor Relations

2010-11 Thomas Nitschka: Momentum in stock market returns: Implications for risk premia on foreign currencies

2010-12 Petra Gerlach-Kristen and Barbara Rudolf: Macroeconomic and interest rate volatility under alternative monetary operating procedures

2010-13 Raphael Auer: Consumer Heterogeneity and the Impact of Trade Liberalization: How Representative is the Representative Agent Framework?

2010-14 Tommaso Mancini Griffoli and Angelo Ranaldo: Limits to arbitrage during the crisis: funding liquidity constraints and covered interest parity

2010-15 Jean-Marc Natal: Monetary Policy Response to Oil Price Shocks

2010-16 Kathrin Degen and Andreas M. Fischer: Immigration and Swiss House Prices

2010-17 Andreas M. Fischer: Immigration and large banknotes

2010-18 Raphael Auer: Are Imports from Rich Nations Deskilling Emerging Economies? Human Capital and the Dynamic Effects of Trade 
2010-19 Jean-Pierre Danthine and John B. Donaldson: Executive Compensation: A General Equilibrium Perspective

2011-1 Thorsten Beck and Martin Brown: Which Households Use Banks? Evidence from the Transition Economies

2011-2 Martin Brown, Karolin Kirschenmann and Steven Ongena: Foreign Currency Loans Demand or Supply Driven?

2011-3 Victoria Galsband and Thomas Nitschka: Foreign currency returns and systematic risks

2011-4 Francis Breedon and Angelo Ranaldo: Intraday patterns in FX returns and order flow

2011-5 Basil Guggenheim, Sébastien Kraenzlin and Silvio Schumacher: Exploring an uncharted market: Evidence on the unsecured Swiss franc money market

2011-6 Pamela Hall: Is there any evidence of a Greenspan put?

2011-7 Daniel Kaufmann and Sarah Lein: Sectoral Inflation Dynamics, Idiosyncratic Shocks and Monetary Policy

2011-8 Iva Cecchin: Mortgage Rate Pass-Through in Switzerland

2011-9 Raphael A. Auer, Kathrin Degen and Andreas M. Fischer: Low-Wage Import Competition, Inflationary Pressure, and Industry Dynamics in Europe

2011-10 Raphael A. Auer and Philip Sauré: Spatial Competition in Quality, Demand-Induced Innovation, and Schumpeterian Growth

2011-11 Massimiliano Caporin , Angelo Ranaldo and Paolo Santucci de Magistris: On the Predictability of Stock Prices: a Case for High and Low Prices

2011-12 Jürg Mägerle and Thomas Nellen: Interoperability between central counterparties 
Swiss National Bank Working Papers are also available at www.snb.ch, section Publications/Research Subscriptions or individual issues can be ordered at Swiss National Bank, Fraumünsterstrasse 8, CH-8022 Zurich, fax+41 4463181 14, E-mail library@snb.ch 